\title{
Tracheal fistula associated with bevacizumab 20 months after mediastinal radiation
}

\author{
Hideto Yamada, Wataru Shigemori, Yasushi Ryujin, Hiroshi Wada, Tetsuya Oguma, Makoto Osawa, \\ Taishi Nagao, Yasutaka Nakano
}

Department of Internal Medicine, Division of Respiratory Medicine, Shiga University of Medical Science, Seta Tsukinowa-cho, Otsu, Japan

Correspondence to Hideto Yamada, otedih@belle.shiga-med.ac.jp

\section{DESCRIPTION}

We report a case of a 60-year-old woman who developed a tracheal fistula 20 months after mediastinal radiation while being treated with bevacizumab. She presented with a large right-sided mediastinal mass given a diagnosis of stage IIIB adenocarcinoma. She was treated with definitive thoracic radiation (figure 1) and a concurrent chemotherapy, including both cisplatin and docetaxel. Eleven months after chemoradiotherapy she developed progressive disease with enlargement of the mass and pleural effusion ipsilateral to the site of the mass. She was treated with pemetrexed as a second-line chemotherapy. Seven months later, she developed progressive disease with bilateral pleural effusion. She received a third-line systemic chemotherapy with carboplatin, paclitaxel and bevacizumab $(15 \mathrm{mg} / \mathrm{kg})$ every 3 weeks. After three cycles, she developed dry cough and fever. Three weeks after her third cycle, she was obtunded with respiratory failure associated with hypercapnia. CT scan showed destruction of the right tracheal wall (figure 2). Non-invasive positive pressure ventilation was used to improve respiratory failure but she and her family would not agree to further attempts, including intubation, stent placement nor surgical repair. She died of respiratory failure several days later.

When administered in combination with thoracic radiation, bevacizumab has been associated with tracheo-

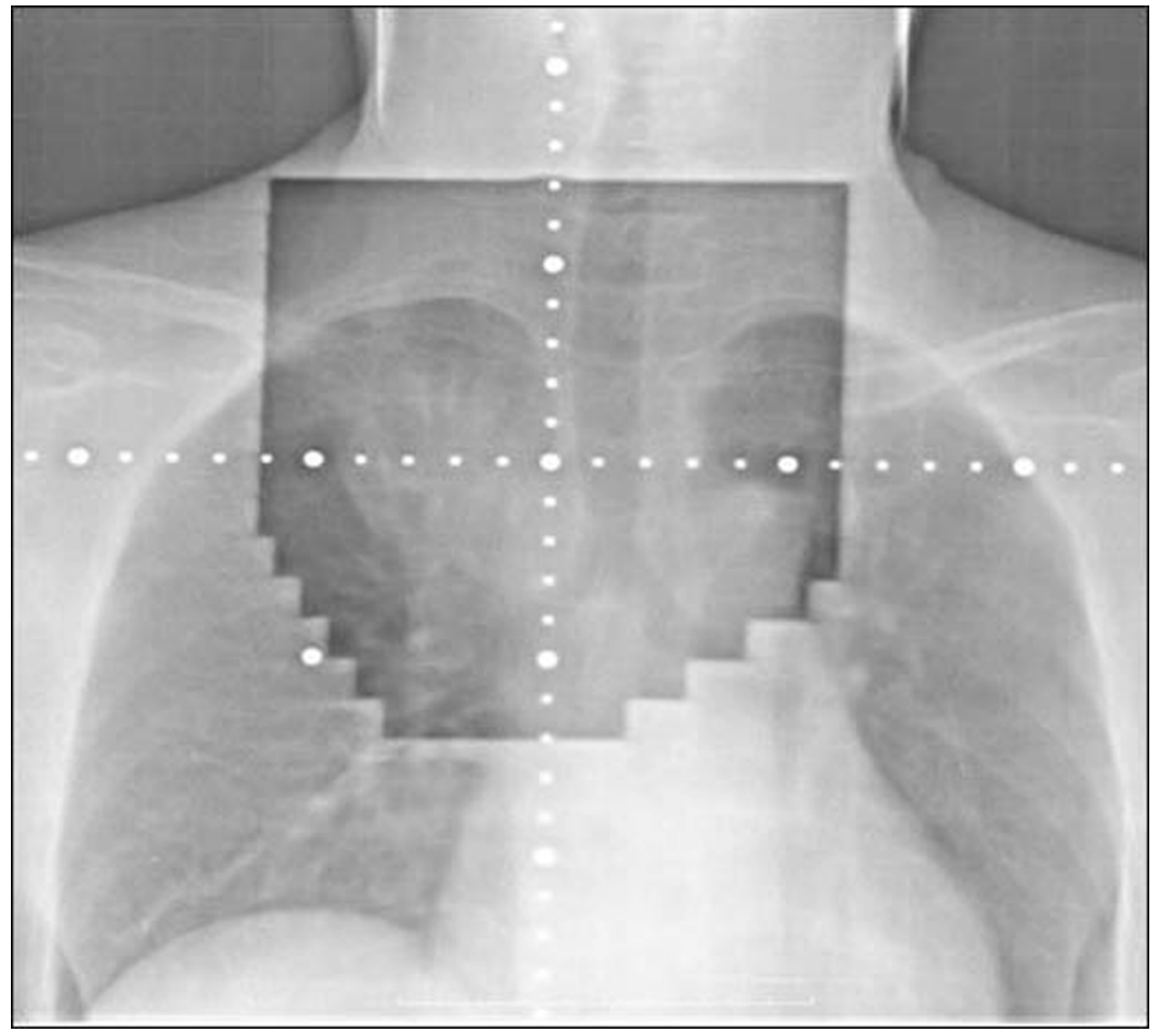

Figure 1 Portal radiograph used for irradiation of adenocarcinoma of the lung, adjacent to the mediastinum, in the right upper lobe with a total dose of $60 \mathrm{~Gy}$. 


\section{BMJ Case Reports}

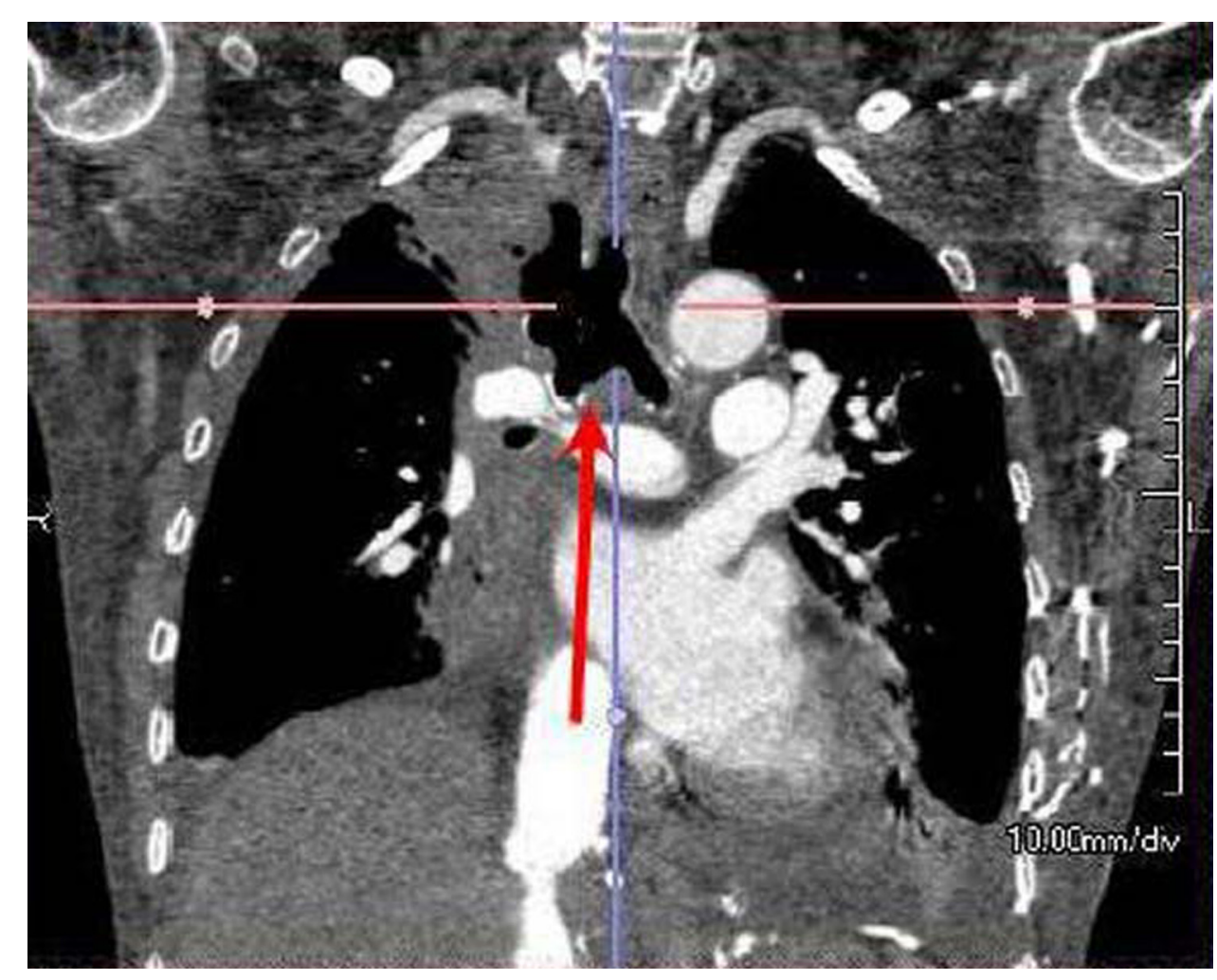

Figure 2 CT scan showed that the right tracheal wall was destructed after the patient received three cycles of third-line systemic chemotherapy, including bevacizumab (red arrow).

oesophageal fistula. ${ }^{1}$ Delayed tracheo-oesophageal fistulae have also been reported in patients treated with bevacizumab even months after chemoradiotherapy. ${ }^{2} 3$ Thus, physicians should be cautious about the formation of lifethreatening fistula in patients with lung cancer treated with bevacizumab after a high dose of mediastinal radiation.

\section{Competing interests None}

Patient consent Obtained.

\section{REFERENCES}

1. Spigel DR, Hainsworth JD, Yardley DA, et al. Tracheoesophageal fistula formation in patients with lung cancer treated with chemoradiation and bevacizumab. J Clin Oncol 2010;28:43-8.

2. Gore $\mathbf{E}$, Currey A, Choong N. Tracheoesophageal fistula associated with bevacizumab 21 months after completion of radiation therapy. J Thorac Oncol 2009;4:1590-1.

3. Goodgame B, Veeramachaneni N, Patterson A, et al. Tracheo-esophageal fistula with bevacizumab after mediastinal radiation. $J$ Thorac Oncol 2008;3:1080-1.

This pdf has been created automatically from the final edited text and images.

Copyright 2010 BMJ Publishing Group. All rights reserved. For permission to reuse any of this content visit http://group.bmj.com/group/rights-licensing/permissions.

BMJ Case Report Fellows may re-use this article for personal use and teaching without any further permission.

Please cite this article as follows (you will need to access the article online to obtain the date of publication).

Yamada H, Shigemori W, Ryujin Y, Wada H, Oguma T, Osawa M, Nagao T, Nakano Y. Tracheal fistula associated with bevacizumab 20 months after mediastinal radiation. BMJ Case Reports 2010;10.1136/bcr.08.2010.3284, date of publication

Become a Fellow of BMJ Case Reports today and you can:

- Submit as many cases as you like

Enjoy fast sympathetic peer review and rapid publication of accepted articles

- Access all the published articles

- Re-use any of the published material for personal use and teaching without further permission

For information on Institutional Fellowships contact consortiasales@bmjgroup.com

Visit casereports.bmj.com for more articles like this and to become a Fellow 